Max Klein, 1941 - 2015

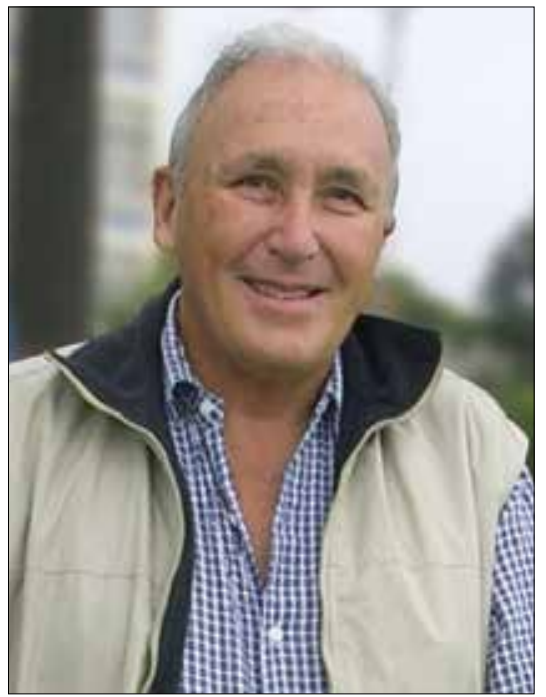

Max Klein passed away suddenly on Tuesday 27 January while doing what he loved, cycling in Stellenbosch. He had made a large contribution to the development of paediatric critical care and paediatric pulmonology in South Africa and beyond.

Max trained as a Wellcome Research Fellow in the first South African neonatal intensive care unit at Groote Schuur Hospital, then as a paediatric registrar at Red Cross War Memorial Children's Hospital, and then in an adult respiratory unit at Stellenbosch University, where he was subsequently appointed as consultant. In 1972 he was awarded a Lilly International Fellowship as a fellow to the Cardiovascular Research Unit and the Department of Paediatrics at the University of California Medical Center in San Francisco, USA.
He returned to South Africa in 1974 to establish the paediatric respiratory service at Red Cross Hospital and the first comprehensive intensive care unit. $\mathrm{He}$ was a strong opponent of apartheid and discrimination, ensuring that this ICU cared for children of all ethnicities. He was the driving force behind its development, led it for 25 years and trained many of the leading paediatric intensivists in South Africa. As recognition of his contribution, he was presented with a gold medal award by the World Federation of Pediatric Intensive and Critical Care Societies in 2000. As an inaugural gold medallist he was recognised as an international pioneer who established the specialty through clinical and academic excellence, dedication to patients and families, and leadership to colleagues.

Max was a brilliant clinician and teacher. $\mathrm{He}$ conducted many pioneering studies in childhood respiratory illness, including the use of CIPP tubes for upper airway obstruction, use of nasal cannulas for oxygen administration, development of a clinical score for the severity of croup, development of continuous positive airway pressure ventilation, and use of vitamin A for children with measles-associated pneumonia. Among his proudest achievements was the home tracheostomy service he started whereby a whole generation of children with respiratory failure could live at home and have the opportunity tolive hopeful lives. In comparing the outcomes of children managed at home with those who were institutionalised, he found the home environment to be much better and wrote: 'Empowerment is the most important principal in rehabilitation. Mother is the most sophisticated technology available in the world; love is of more consequence to the child than physical comfort. Intelligence is not related to literacy and best care is not necessarily more costly care.'

Max was the first Extraordinary Professor in the Department of Paediatrics and Child Health at the University of Pretoria. He made an invaluable contribution to starting the Paediatric Pulmonology Fellowship training programme and to teaching, training and research.

Max will be remembered as a fearless opponent of injustice, an outspoken critic for things he believed in, a man of uncompromising integrity, a master clinician and teacher, and an innovator with a real vision for the development of services in paediatric critical care, pulmonology and other areas of child health.

\section{Heather Zar}

Department of Paediatrics and Child Health, Red Cross War Memorial Children's Hospital, Cape Town, and Faculty of Health Sciences, University of Cape Town, South Africa heather.zar@uct.ac.za

\section{Robin J Green}

Department of Paediatrics and Child Health, School of Medicine, Faculty of Health

Sciences, University of Pretoria, South Africa robin.green@up.ac.za

\section{Eugene Weinberg}

Emeritus Professor, Paediatrics and Child Health, Faculty of Health Sciences, University of Cape Town

weinberg@yebo.co.za 
In his second undergraduate year, Max Klein developed meningococcal meningitis. Within a few hours he was moribund and pulseless. As the senior house officer on duty, I was obliged to attend to him until expert help could be summoned. After the event, he claimed that his brain had never been clearer! This did not restrain him from admonishing us for perceived lapses in patient care, and throughout his professional life he viewed diagnosis and treatment from a patient perspective and expected his staff to do likewise.

We met again as neonatal research colleagues at Groote Schuur Hospital. Here I got to know the post-meningococcal brain intimately. Its originality of thought was astounding, and I shall be ever grateful for being advised to read The Art of Scientific Investigation by $\mathrm{W}$ Beveridge. Research time became playtime, and we pursued numerous exciting ideas in the hope of making discoveries. Now for the sad part.
A discovery does not exist until it is in print, and Max had a writing block. His numerous unpublished findings languished for decades - surprising, for later in his career he became a prolific author. Nevertheless he imparted his treasures to those around him, and his clinical acumen was unsurpassable. He developed special surgical skills, probably as a result of a stint in Chris Barnard's animal unit in his student years. His simple yet unique methods of tracheostomy and chest drain insertion were adopted by all.

Inevitably our ways parted, as each pursued a subspecialty. After a stint at the Californian Cardiovascular and Pulmonary Institute, Max returned to Red Cross Children's Hospital where he established a department for lung ailments and an intensive care unit. The latter took its toll, for when he retired, he stated: 'I have experienced the deaths of 2200 children, and that's enough.' He never tolerated fools or injustices, but in later years he could be infuriatingly unco-operative. This, I believe, was the result of unrelenting exposure to sick and dying children.

In retirement we were reunited, and each week for ten years we walked the length and breadth of Cape Town and Sydney discussing ideas, books and characters. Several months before Max's untimely death he gave up walking because of a knee ailment and concentrated on cycling. This he enjoyed immensely, and it was during a ride that he quietly and suddenly departed from this world. He was unique, and with his inexplicable creative powers, a genius - the like of which will not be seen again.

\section{C Harrison}

3 Hurley Road, Mowbray, Cape Town, South Africa

vincentcostelloharrison@gmail.com 